\title{
Critical and Creative Thinking
}

SHARON BAILIN

\section{Introduction}

A central goal of contemporary education is to improve the thinking skills of students, and the notions of critical thinking and of creative thinking provide focusses for this effort. As educators we would like our students to be better critical thinkers. This implies thinking more effectively within curricular subject areasunderstanding the reasoning employed, assessing independently and appropriately, and solving problems effectively. It involves, as well, improved thinking skills in dealing with real life problems - in assessing information and arguments in social contexts and making life decisions. We also want students to be more creative-not simply to reproduce old patterns but to respond productively to new situations, to generate new and better solutions to problems, and to produce original works.

These goals of fostering critical thinking and of fostering creativity are generally considered to be quite separate and distinct. Critical thinking is seen as analytic. It is the means for arriving at judgments within a given framework or context. Creative
University of Manitoba

thinking, on the other hand, is seen as imaginative, constructive, generative. It is what allows for the breaking out of or transcending of the framework itself. There is, however, disagreement among theorists as to the relationship between the two types of thinking. Some view them as different but complementary. Glaser, for example, states, "Creativity supplements critical thinking. It may not be an essential ingredient in critical thinking. "[1] Other theorists such as De Bono believe that there is a tension between critical and creative thinking, that breaking out of a prevailing framework requires an abandonment of the logic and standards for critical assessment which characterize the framework. Both groups are in accord, however, in the belief that critical and creative thinking are fundamentally different and that they therefore require different pedagogies. The complementarity view usually entails efforts to teach critical thinking skills on their own or integrated into curricular materials plus techniques to encourage flexibility, spontaneity, divergent thinking, etc. The opposition view usually involves the abandonment of some 
aspects of critical thinking and disciplinary skills in favour of such creativity techniques, on the grounds that the former are inhibiting to the latter. De Bono makes the latter point thus: "Too much experience within a field may restrict creativity because you know so well how things should be done that you are unable to escape to come up with new ideas. "[2]

I believe that there are serious conceptual and educational problems in this radical dichotomy between critical and creative thinking. I shall argue that there are analytic, highly judgmental aspects to generating creative results, and imaginative, inventive aspects to being critical, and that it is exceedingly difficult to neatly separate out two distinctive kinds of thought. Moreover, I will demonstrate the problematic educational outcomes of the view of thinking on which this separation rests-outcomes such as a basic curriculum in the schools which is static and encourages appeal to authority, a consequent picture of knowledge in general as authoritarian, the notion of critical thiking as a set of isolatable add-on techniques, and a downplaying of skills and knowledge in favour of intuition and irrationality in the name of creativity. Finally, I would like to try to give a sense of what difference it might make educationally to view critical thinking and creative thinking as joint and inseparable goals.

\section{The Standard View}

The standard view about the nature of critical thinking and of creative thinking which underpins much contemporary psychological and educational theory and practice sets up a sharp separation between the two. According to this view, critical thinking involves arriving at assessments within specific frameworks. It is the means for making reasoned judgments within these frameworks based on the standards of judgment inherent in the framework.
It is thus essentially analytic, evaluative, selective, and highly rule-bound. Given the necessary information from within the framework and the appropriate techniques of reasoning, arriving at judgments is almost algorithmic. In thinking critically one is, however, confined to the specific framework. Because it is circumscribed by the logic of the framework, critical thinking cannot provide the means to transcend the framework itself nor to question its assumptions. De Bono puts the point as follows: "Logial thinking can never lead to that alteration of sequence that leads to the 'insight' rearrangement of information... Logical thinking may find out the best way of putting together $A, B$ and $C$ but it will not discover that $A, B$ and $C$ are inappropriate units anyway". [3]

Creative thinking, on the other hand, is precisely the type of thinking which can transcend frameworks. It is inventive, imaginative, and involves the generation of new ideas. Because it involves breaking out of old frameworks, creative thinking is thought to exhibit characteristics which are precisely the opposite of critical thinking. It is essentially generative, spontaneous, and non-evaluative. It involves divergent thinking, rulebreaking, the suspension of judgment, and leaps of imagination. And, instead of being characterized by logic or appeal to reasons, it relies heavily on intuition, and unconscious processes. This dichotomy is evident in Koestler's contrast between disciplined thought and the creative act: "ordered, disciplined thought is a skill governed by set rules of the game, some of which are explicitly stated, others implied and hidden in the code. The creative act, in so far as it depends on unconscious resources, presupposses a relaxing of the controls and a regression to modes of ideation which are indifferent to the rules of verbal logic, unperturbed by contradiction, untouched by the dogmas and taboos of so-called common sense."'[4] 


\section{A Flase Dichotomy}

I believe, however, that this opposition between critical thinking and creative thinking is false, and that it is mistaken to view them as radically different and unconnected. First, it can be shown that thinking critically plays a crucial role in innovation. Innovation must be viewed in terms of creating products which are not simply novel but also of value, and critical judgment is crucially involved in such creative achievement. In any creative solution to a problem, the initial recognition that there is a problem to be solved, the identification of the nature of the problem, and the determination of how to proceed all involve critical assessment. Initally, the realization that there is a problem to be solved, that there are phenomena in need of explanation or exploration involves judgment. The recognition that a new direction or approach is required is an evaluation based on knowledge and an understanding of the problem situation. And there is judgment involved in determining the general range and form of possible solutions to problems or next moves in creating, the ideas and directions that might be fruitful, and even the ideas that will count as solutions or achieve the completion of a work. Thus the idea that creative thinking is not dependent upon critical thinking will not hold up under scrutiny.

Second, the idea that creative thinking is essentially rule-breaking can also be questioned. It is frequently the case that innovation requires the breaking of a rule or rules of the framework in question, but it is generally only very few rules that are broken. The majority remain intact, rules which give coherence to the activity as essentially rule-breaking largely ignores the background of rules and rule-governed activity against which any creation occurs and the continuity between an innovation and that which precedes it.

This continuity points to the fact that creative thinking is not grounded in irrational processes but is, in fact, a reasonable response to a problem situation. Creativity is not merely a question of generating new solutions to problems, but of generating better solutions, and is thus not a matter of arbitrary novelty or random invention, but involves change which is effective, useful, and significant. Such change is connected with high-level skills and in-depth knowledge in an area, with a profound understanding of the problem situation and with attempts to solve these problems in ever better ways. This implies highly developed critical judgment. Critical thinking is, thus, intimately involved in creative production.

I think that it can also be demonstrated that critical thinking is not merely analytic, selective, and confined to frameworks, but has imaginative, inventive, constructive aspects. Definitions of critical thinking generally make reference to assessing on the basis of reasons (eg. Ennis: "the process of reasonably deciding what to believe or do" [5]; Siegel: "being appropriately moved by reasons" [6]), but such assessments are not generally clear-cut or mechanical. They require an imaginative contribution on the part of the assessor. Even within traditional subject areas which are considered technical, the reasoner must go beyond the confines of the given information, supplying imaginative constructs. Perkins has made this point with respect to mathematics: "The evident challenge posed by many mathematical problems plainly calls upon the problem solver's powers of invention. To be sure, if a mathematical problem allows a solution by sheer guesswork or systematic computation, with no need to discover a path from given to answer, then imagination need play no role. But virtually all serious mathematical problems do not surrender so easily, else they would not count as serious." [7]

This is all the more true in the case of informal reasoning, where considerable invention is required of the 
reasoner. Even in the case of assessing individual arguments according to the criteria of informal logic, the procedure is not merely technical or algorithmic. Identifying assumptions, inventing hypotheses, generating counter-examples and constructing counter-arguments are all examples of aspects of informal reasoning which require imagination. As Ennis has pointed out, such reasoning activities as observing, inferring, conceiving alternatives, and offering a well organized line of reasoning are all activities in which "the thinker contributes more than evalutation to the result." [8] And Scriven sums up this point nicely when he states, "the very process of criticism necessarily involves the creative activity of generating new theories or hypotheses to explain phenomena that have seemed to other people to admit of only one explanation.' '[9]

Moreover, critical thinking involves more than assessing isolated arguments according to clearly-defined criteria and using specifiable techniques, as Richard Paul has pointed out in his critique of 'weak sense' critical thinking.[10] In actual instances of critical reasoning, it is rarely the case that we pass definitive judgment on isolated arguments. Rather, we judge between conflicting points of view, and adjudicate among competing arguments. And certainly the criteria of informal logic provide one basis for so doing. Yet such criteria are seldom decisive in and of themselves, and what the reasoner must do is to construct a new view which resolves the problems posed by the conflicting views and synthesizes the soundest aspects of each into a new and coherent whole. Even in those cases where one of the views is, in the end, wholly accepted or rejected, serious assessment must involve an understanding of the strengths of both views, and a 'sympathetic reconstruction' of the strongest arguments for each, as Paul puts it.[11] This dialectical aspect of critical thinking is one which has been pointed out by numerous theorists including
Paul, Glaser, and Perkins, and it is an aspect of critical thought which clearly requires imagination and invention.

One reason for this dichotomized view of thinking into the critical and the creative might be connected with the notion of frameworks. According to this view, ordinary thinking takes place within rigidly bounded and highly rule-govenred frameworks, disciplinary particularly true within disciplinary areas and especially technical ones. Within these frameworks, all necessary information is given, and the mode of thinking required is analytic and evaluative, involving judgments made almost mechanically according to the logic of the framework. Given this picture of frameworks, it would seem to follow that a radically different type of thinking is required to transcend frameworks, a type of thinking which suspends the criteria of judgment of the framework, breaks rules, which makes irrational leaps, and which generates novelty. This is the line taken by De Bono, as the following quote demonstrates:"A frame of reference is a context provided by the current arrangement of information. It is the direction of development implied by this arrangement. One cannot break out of the frame of reference by working from within it. It may be necessary to jump out, and if the jump is successful then the frame of reference is itself altered." [12]

I would argue, however, that this view of how frameworks operate is mistaken. In actuality, there are only a very limited number of cases in which we operate within clear-cut, clearly determined, and rigidly bounded frameworks. In most situations which require critical thought, frameworks overlap, shift, and have indefinite boundaries. Even within traditional disciplines, one is not dealing with static and rigid bodies of information. Rather, disciplines are openended and dynamic. They involve not merely information, but also live questions and modes of investigating these questions. And even the body 
of facts is not fixed but is in flux. There are open questions, ongoing debates, and areas of controversy within every discipline, and these furnish the arena for evolution and change. Thus the rigid framework model does not appear to be accurate even within disciplinary areas

This fluid aspect to frameworks is even more apparent in inter-disciplinary and real life problem contexts. In such situations, relevant considerations are seldom confined to one framework, but involve, rather, information from a variety of perspectives and frames of reference. As Paul states with reference to such real life problems, "We cannot justifiably assume that any one frame of reference or point of view is pre-eminently correct, as the perspective within which these basic human problems are to be most rationally settled." [13] Moreover, even the notion of a clearly defined framework has limited applicablity in such contexts. What, for example, would be the framework for thinking about questions regarding war and peace or concerning love and human relationships? Once it is recognized that frameworks have this fluid, indeterminate character, the case for two separate and distinct modes of thinking, one for operating within and the other for transcending frameworks, is considerably weakened.

I would contend, then, that critical thinking and creative thinking are not separate and distinct modes of thinking which operate within different contexts and to different ends. Rather, they are intimately connected and are both integrally involved in thinking well in any area. In all instances in which serious thinking is required, both the constraints of logic and the inventiveness of imagination come into play. There is some degree of creativity evident in all critical thinking, and in some cases, deliberations over what to reasonably believe or do lead one to question presuppositions or break rules-and issues in products which display considerable novelty. This is not connected with irrational leaps, but rather with a broad and in-depth understanding of the problem situation and of what is really at issue. Truly critical thought aims at the best judgments, actions, and outcomes and what is better is necessarily also new. Thus the critical and the creative are inextricably linked and are joint aspects of effective thinking.

\section{Education}

This radical separation of critical and creative thinking has its source in a specific picture of thinking and knowledge, namely that ordinary thinking is convergent, analytic, and takes place within rigid frameworks, and that creative thinking requires imaginative leaps to transcend the frameworks. This picture has, I think, held considerable sway in educational circles and has had what I believe to be a detrimental effect on the way we teach in schools. As a product of this picture, the various subject areas are conceived of as defined and fixed bodies of knowledge, static collections of facts to be assimilated and recollected. Students are thus left with a sense that knowledge is complete, definite, and fixed, and that it is based on an appeal to authority-be it of the text, of the teacher, of the unnamed 'they' who say that it is so. Theorists and educators have certainly realized the inadequacy of this approach and have attempted to introduce critical thinking into the curriculum, either as a subject on its own, or in conjunction with disciplinary materials. Some theorists have also noted that this traditional type of curriculum can be stultifying and deadening to creativity and so have advocated techniques to encourage creative thinking. Thus we see a proliferation of techniques such as brainstorming and the random stimulation of ideas which purport to foster creativity. In the best case, these are seen as an adjunct to disciplinary skills and knowledge and to critical thinking skills. In the worst case, 
disciplinary skills and knowledge and critical thinking skills are viewed as inhibiting to creativity because they lock one into a prevailing framework and so such skills are neglected or considerably downplayed in favour of irrational processes.

It seems to me that such efforts to counteract the inadequacies of the traditional curriculum are insufficient in the case of critical thinking and sometimes misguided in the case of creativity. They are both supplemental measures which do not attack one root of the problem, namely the picture of knowledge as complete, definite, and fixed. Such measures will remain remedial unless teaching and learning in subject areas begins to reflect the critical and creative nature of knowledge itself. Disciplines are not merely static collections of information but are modes of inquiry, containing open questions, areas of controversy, and ongoing debates. Mechanisms for criticism and thereby for evolution are built right into the disciplines themselves, and students must gain a sense of this in the way subjects are presented or it is unlikely that the hold of the authoritarian picture of knowledge will be broken. Criticism must be understood as part of the subject matter itself, as part of what it means to learn a discipline, as the method whereby inquiry proceeds. And it must be understood that the possibility for evolution and innovation is afforded by the critical and dynamic nature of disciplines and does not require an abandonment of disciplinary skills nor a reliance on irrational processes.

I also suspect that this dichotomized view of thinking and this picture of knowledge as definite and fixed which is created by the traditional school curriculum extends, as well, into thinking in non-disciplinary areas and is one reason why it is so difficult to enhance the critical thinking skills of students. They are accustomed to seeking the right answer according to authority and to expecting algorithmic solutions to problems and this is their mode of proceeding with respect to life problems as well. On the other hand, they may aim for creativity which, they have learned, can be achieved by thinking divergeritly, relying on subjective personal opinion, and ignoring critical criteria for assessment. I believe that it is crucial that students learn that there is a path between dogmatism and ignorance. It is vital that they understand that thinking well in any area is based on knowledge, but is questioning and critical according to sound reasons, and that creativity is an extension of thinking really well about problems. They need to acquire a sense that knowledge is made, developed and advanced, but that this takes place within the constraints of logic and the principles and goals of the relevant area.

What, then, am I suggesting with respect to education? First, I am arguing that the notion that disciplinary knowledge and critical thinking skills are inhibiting to creativity is mistaken, and that, in fact, the possibility for advancement and innovation in any area rests on a thorough and in-depth understanding of the state of the art of the discipline and on highly developed critical judgment. Thus I am advocating that we really emphasize mastery of disciplinary knowledge and skills as a precondition for any creative achievement. This must include, not merely the current body of information, but also the principles and procedures of the discipline, the methods whereby inquiry proceeds, the standards according to which reasons are assessed, and the over-all goals and deep questions which are at issue. Thus the critical nature of knowledge and knowledge growth must be stressed.

In addition, we must communicate a sense that thinking and knowledge are creative. This implies an understanding that disciplinary knowledge is not static and rigidly circumscribed within a fixed framework, but is dynamic, taking place within overlapping and fluid frameworks, and that 
it grows and develops. Knowledge must be understood not as an authoritative body of facts, but as something made by people who are thinking well about problems. This type of picture of knowledge as dynamic, non-authoritarian and creative would, I think, give rise to a more critical attitude on the part of students with respect to thinking in all areas.

This creative aspect to all thinking must also be taken into account in the teaching of critical thinking. Critical thinking consists in more than isolated technical skills, although such skills are an indispensable starting point. It generally takes place in contexts which are not clearly defined nor totally specified, and in situations which are dynamic, and the reasoner must make an imaginative contribution to the assessment. This points to the necessity to present critical thinking skills within real and dynamic contexts, and to encourage the ability to reconstruct opposing arguments and to develop an independent line of reasoning. The dialectical aspect of critical thinking is thus emphasized by the recognition of the creativeness of critical thinking.

McKellar, in his book Imagination and Thinking, gives the following description of the attitude which he feels is most conducive to creativity: "serious receptivity towards previous thought products and unwillingness to accept them as final'".[14] This is, I think, a very good characterization of the kind of attitude toward thinking and knowledge which comes out of an understanding of the close interconnection of the critical and the creative. Taking previous thought products seriously implies recognizing the importance of knowledge and skills, of judgment, of in-depth understanding, and of criticism and reasons in creative production. Unwillir.gness to accept such products as final entails an understanding of the dynamic, lively, evolutionary nature of knowledge and the creative nature of criticism. Both these aspects are crucial in any attempt to improve the thinking of our students both within disciplinary areas and with respect to real life problems. Thus I would advocate the encouragement of critical thinking and of creative thinking as joint and inseparable goals in education. [15]

\section{Notes}

[1] E. Glaser, "Critical Thinking: Educating for Responsible Citizenship in a Democracy," National Forum (1985) pg. 25.

[2] E. De Bono, Practical Thinking. Middlesex: Penguin Books, 1976, pg. 165.

[3] E. De Bono, The Mechanism of Mind. Middlesex: Penguin Books, 1969, pg. 228.

[4] A. Koestler, The Act of Creation. London: Pan Books, 1975, pg. 178.

[5] R. Ennis, "Rational Thinking and Educational Practice." In J. Soltis (ed.), Philosophy of Education (80th yearbook of the National Society for the Study of Education, vol. 1), Chicago: The National Society for the Study of Education, 1981.

[6] H. Segel, "Critical Thinking as an Educational Ideal," Educational Forum, November 1980, pp. 7-23.

[7] D. Perkins, "Reasoning as Imagination." In S. Bailin, D. Perkins, and I. Winchester (eds.) Creativity, Education, and Thought, (Interchange, 16,1 1985),pp.15-16.

[8] R. Ennis, "A Conception of Rational Thinking." In J. Coombs (ed.), Philosophy of Education 1979, pg. 5.

[9] M. Scriven, Reasoning, NY: McGraw-Hill, 1976, pg. 36.

[10] R. Paul, "Teaching Critical Think- 
ing in the Strong Sense: A Focus on Self-Deception, World Views, and a Dialectical Mode of Analysis," Informal Logic 4, 2 (1982), 2-7.

[11] R. Paul, "Critical Thinking and the Critical Person," in D. Perkins, J. Lockhead and J. Bishop (eds.) Thinking: The Second International Conference, Hillsdale, N.J.,: Earlbaum, 1987, pp. 373-403.

[12] De Bono, The Mechanism of Mind, pg. 240.

[13] R. Paul, "Critical Thinking and the Critical Person."
[14] P. McKellar, Imagination and Thinking. London: Cohen and West, 1957, pg. 116.

[15] I am grateful to Harvey Siegel and to Rodney Clifton for their helpful suggestions on the manuscript. An earlier version of this paper was presented at the Fourth International Conference on Critical Thinking and Educational Reform at Sonoma State University, Sonoma California, August, 1986.

Dr. Sharon Bailin, Faculty of Education, University of Manitoba, Winnipeg, Manitoba R3T 2N2 